\title{
Short communication: Comparison of estrus characteristics in Holstein heifers by 2 activity monitoring systems
}

\author{
B. F. Silper, A. M. L. Madureira, M. Kaur, T. A. Burnett, and R. L. A. Cerri ${ }^{1}$ \\ Faculty of Land and Food Systems, University of British Columbia, Vancouver V6T 1Z4, BC, Canada
}

\begin{abstract}
Two activity monitoring systems-Heatime (SCR Engineers Ltd., Netanya, Israel) and IceTag (IceRobotics Ltd., Edinburgh, UK) - were compared on their ability to detect and quantify estrus expression. Holstein heifers $(\mathrm{n}=57)$ were fitted with Heatime (HT) and IceTag (IT) sensors from 12 mo of age until confirmation of pregnancy. Upon detection of high activity by HT, ovaries were scanned by ultrasound, a blood sample was collected for analysis of plasma estradiol, and signs of estrus (clear vaginal mucus, uterine muscle tone, visual mounting activity, standing to be mounted, or rump showing signs of repeated acceptance of mounts) were recorded. Because only estrus episodes detected by $\operatorname{HT}(\mathrm{n}=111)$ were further evaluated, only the positive predictive value was measured. Heifers were housed in groups of 24 in a freestall pen. Data were analyzed using Proc CORR and GLM of SAS (SAS Institute Inc., Cary, NC). The positive predictive value was $84.7 \%$ (94/111) for HT and $98.7 \%$ (74/75) for IT. Estrus duration was recorded by HT as $14.3 \pm 4.1 \mathrm{~h}$ $[$ mean \pm standard deviation (SD)] and by IT as 15.0 $\pm 4.0 \mathrm{~h}$; duration measurements were correlated $(\mathrm{r}=$ $0.60)$. The mean duration difference was $0.74 \pm 3.52 \mathrm{~h}$. Recordings of onset and end of estrus by IT were 3.5 $\pm 4.3 \mathrm{~h}$ and $2.9 \pm 4.9 \mathrm{~h}$ earlier than those by HT. The overlap in duration was $9 \mathrm{~h}$. Measurements of estrus intensity were correlated $(\mathrm{r}=0.63)$. Peak activity was $77.3 \pm 19.5$ index value (approximately $7.7 \mathrm{SD}$ from basal activity) on HT. The relative increase in activity measured by IT was $360 \pm 170 \%$ baseline value. Measurements of intensity and duration from HT were correlated $(\mathrm{r}=0.64)$ but those from IT were not $(\mathrm{r}$ $=0.13)$. Plasma estradiol concentration (11.2 \pm 4.6 $\mathrm{pg} / \mathrm{mL}$ ) was not correlated with preovulatory follicle diameter or with duration or intensity of estrus. Diameter of preovulatory follicle $(15.7 \pm 2.6 \mathrm{~mm})$ had no correlation with duration of estrus and was only weakly correlated with intensity measured by either system.
\end{abstract}

Received December 2, 2014.

Accepted January 21, 2015.

${ }^{1}$ Corresponding author: ronaldo.cerri@ubc.ca
Baseline steps/hour was negatively correlated with intensity from both sensors $(\mathrm{r}=-0.37$ and -0.70 for HT and IT). Estrus episodes accompanied by 2 or 3 of the monitored signs of estrus had greater intensity and duration on HT but not on IT. Preovulatory follicle diameter and plasma estradiol concentration did not influence occurrence of estrus signs. Results indicate that both systems identified estrus precisely, with correlated characterization and similar timing. In contrast, relationships with plasma estradiol concentration and signs of estrus require further investigation.

Key words: accelerometer, dairy, estrus detection, pedometer

\section{Short Communication}

Accurate detection of estrus is a key factor for good reproductive performance of dairy herds (Nebel et al., 2000; Roelofs et al., 2010). Traditional methods for detection of estrus include observation of standing to be mounted behavior and secondary signs such as mounting other cows, restlessness, clear vaginal mucus, and swollen vulva (Rae et al., 1999; Roelofs et al., 2005, 2010). Efficient visual observation of estrus, however, has high labor demands, besides a detection rate of $54 \%$ (At-Taras and Spahr, 2001). Failure to detect estrus behaviors and false estrus detection can result in missed or untimely inseminations, which leads to poor reproductive efficiency and economic losses on dairy farms (Rae et al., 1999).

Focusing on the characteristic restlessness and increased physical activity displayed by cows in estrus, tools for automated measurement of movement have been under development for almost 40 yr (Kiddy, 1977). These automated detection systems have the potential to detect estrus more effectively and precisely than visual observation alone. The investigation of characteristics such as duration of estrus, time of estrus onset, breed differences, synchronized estrus expression, and ideal timing of AI in relation to onset of estrus (Rae et al., 1999; Nebel et al., 2000) is possible with the use of automated detection systems. The most commonly used automated detection systems are pedometers, accelerometers, and mount detectors (Senger, 1994; At- 
Taras and Spahr, 2001; Roelofs et al., 2010; Silper et al., 2015).

The objectives of this study were to assess detection rates and quantify the degree of estrus expression according to 2 activity monitoring sensors worn simultaneously by Holstein heifers at breeding age. Heatime (SCR Engineers Ltd., Netanya, Israel) is a commercial collar-mounted activity monitoring system, which transfers data wirelessly to a station every $2 \mathrm{~h}$ and generates real-time high activity alerts for individual cows. IceTag (IceRobotics Ltd., Edinburgh, UK) is a leg-mounted, research-based sensor, which measures number of steps and standing and lying times on a per-minute basis. Data were downloaded from IceTags once weekly; therefore, identification of estrus with this system was retrospective.

Previous research reported that Heatime correctly identified $72 \%$ of preovulatory phases but also identified some activity peaks during high-progesterone periods (Aungier et al., 2012). IceTag sensors have been validated for step counting by comparison with video recording (Nielsen et al., 2010). Those authors recognized that IceTags accurately estimate steps during walking periods, although some "false steps" may occur. Use of IceTags for detecting estrus has been validated with research-developed algorithms for up to 93\% sensitivity (McGowan et al., 2007). Jónsson et al. (2011) also developed algorithms for detection of estrus with IceTag step counts, with $89 \%$ sensitivity and $99 \%$ specificity.

The present study was conducted at the University of British Columbia's (UBC) Dairy Education and Research Centre (Agassiz, BC, Canada) from May 2012 to August 2013. The local Institutional Animal Care Committee following the requirements of the Canadian Animal Care Council (CACC) approved all experimental procedures.

Fifty-seven Holstein heifers were group-housed in a sand-bedded freestall pen $(13.0 \times 14.5 \mathrm{~m})$ with rubber flooring on both alleys. The group was composed of 24 heifers, which were moved into the pen at 12 mo of age and moved out at the first positive pregnancy diagnosis. A TMR was offered once daily at $0900 \mathrm{~h}$ and pushed up 3 times/d (at approximately 1100, 1800, and $2200 \mathrm{~h}$ ). Water was available at all times.

Heatime tags were attached to the upper left side of a collar worn at the cranial portion of the heifer's neck. These tags are accelerometers that send data wirelessly every $2 \mathrm{~h}$ to a receiving unit connected to a computer. A cow's activity is translated into an index value that represents weighted standard deviations from each cow's own basal activity. Index values range from 0 to 100; the threshold for an episode of high activity was set at an index value of 35 . Data were exported from the Heatime software and converted into Excel files (Microsoft Corp., Redmond, WA) using the Heatime batch tool. An Excel macro was developed and validated to identify episodes of high activity. Estrus onset hour, end hour, and duration according to the timeframe above the threshold were obtained for each high activity episode from the macro-edited files. The maximum index value observed at an estrus episode was defined as "peak index value" and represents the measurement of estrus intensity for Heatime.

IceTag sensors were attached with custom flexible plastic straps to the metatarsal region, on one of the heifer's hind limbs. Data were downloaded once weekly with the IceReader unit connected to a laptop using the IceTag Analyzer 2011 software (IceRobotics Ltd.). Because download and reactivation did not require removal of the sensor from the heifer's leg, there was a recording gap of only 10 min between 2 consecutive files.

Estrus episodes were identified from IceTag step counts following the methodology described by Silper et al. (2015). In summary, peaks of activity (potential estrus episodes) were identified in a chart of the rolling sum of steps over 24-h periods. After detection of activity peaks, the start and end times of each episode were determined based on the summed frequency of steps per 2 -h blocks. The 90th percentile of the number of steps for all 2-h blocks during a 1-wk period surrounding the day of estrus (day of activity peak $\pm 3 \mathrm{~d}$ ) was calculated. The 2-h blocks that met or exceeded the 90th percentile were used to compose the estrus period and determine the hour of onset and end of the estrus period. Total duration and total number of steps during the estrus episode were calculated as the sum of all 2-h blocks that comprised the estrus cluster. Baseline steps were calculated as the mean frequency of steps for the same 2-h blocks of $3 \mathrm{~d}$ preceding the estrus cluster. Total estrus steps and total baseline steps divided by estrus duration are presented as estrus steps $/ \mathrm{h}$ and baseline steps/h. Relative increase in activity was defined as [(total estrus steps - total baseline steps)/ total baseline steps] $\times 100 \%$.

Estrus characteristics were evaluated at each high activity episode identified by Heatime. The Heatime software was checked for new estrus episodes thrice daily. Once a new estrus alert was observed, a blood sample was collected immediately. Blood samples (10 $\mathrm{mL}$ ) were collected from the coccygeal artery or vein in $\mathrm{K}_{2}$ /EDTA vacuum tubes (Becton Dickinson Vacutainer Systems, Rutherford, NJ) to determine plasma estradiol concentration. Samples were centrifuged $(1,565 \times$ $g$ for $15 \mathrm{~min}$ at $5^{\circ} \mathrm{C}$ ), and plasma was harvested and stored frozen at $-80^{\circ} \mathrm{C}$. Estradiol concentration was determined by RIA (Kirby et al., 1997). Ovaries were 
scanned by ultrasonography (Ibex Pro, equipped with a $7.5-\mathrm{MHz}$ linear rectal transducer; EI Medical Imaging, Loveland, CO) to describe and measure ovarian structures in the a.m. or p.m. period after Heatime generated a new high activity alert. Signs of estrus were assessed at the time of ovarian ultrasonography (clear vaginal mucus, uterine tone, visual mounting activity, standing to be mounted, or rump showing signs of repeated acceptance of mounts).

Heifers were inseminated artificially if on-farm evaluation judged the alert as a true estrus. Peak index value, days from last estrus, ovarian structures, and estrus signs were considered for this decision. Precision of estrus detection was retrospectively determined from ovarian dynamics and plasma estradiol concentration.

Because only heifers detected by the Heatime system were evaluated, performance could only be measured by positive predictive value (i.e., true detected episodes/ all detected episodes). Estrus episodes were classified as true estrus or not, and as detected by Heatime only, or by Heatime and IceTag.

Means \pm standard deviations (SD) and distributions were obtained with Proc UNIVARIATE (SAS version 9.3, SAS Institute Inc., Cary, NC). Intensity and duration of estrus were studied as variables characterizing the degree of estrus expression. Estrus intensity is represented by peak index value (Heatime) and relative increase in walking activity (IceTag). Number of steps/hour during estrus and during baseline (mean of $3 \mathrm{~d}$ before estrus) were also reported. Timing of estrus detection was assessed by hour of onset and end of high activity episodes. Period of overlapped high activity and differences of duration, onset, and end hour were used to compare timing among systems. Correlations between measurements of intensity and duration within and between systems were determined with Proc CORR. Correlations were also determined for the relationship between physiological measurements (diameter of preovulatory follicle and plasma estradiol concentration) and automated measurements (intensity and duration of estrus measured by either system). False-positive estrus alerts were excluded from the correlation analysis between physiological and automated measurements.

The relationship between automated measurements of estrus expression and observed signs of estrus (clear vaginal mucus, uterine tone, visual mounting activity, standing to be mounted, or rump showing signs of repeated acceptance of mounts), preovulatory follicle diameter, and plasma estradiol concentration were analyzed by ANOVA using Proc GLM with heifer as the random variable. The following measurements were analyzed as categorical variables: number of estrus signs (0 to 3$)$, diameter of preovulatory follicle $(\leq 15$ $\mathrm{mm}=$ small $;>16 \mathrm{~mm}=$ large $)$, and plasma estradiol concentration $(<11.2 \mathrm{pg} / \mathrm{mL}=$ low; $\geq 11.3 \mathrm{pg} / \mathrm{mL}=$ high). Continuous variable results were described as means \pm SD for purely descriptive statistics and as least squares means \pm standard errors of the mean when comparisons were calculated (e.g., intensity and duration of estrus according to the number of estrus signs).

A total of 119 episodes from 57 Holstein heifers at breeding age were evaluated. Heatime $(\mathrm{n}=111)$ gave real-time activity information, allowing for ultrasound scanning of ovaries, collection of blood sample, and assessment of signs of estrus at the beginning of the estrus episode. Data from IceTag sensors were evaluated retrospectively and compared with Heatime measurements of estrus expression.

Intensity of estrus recorded by Heatime was 77.3 \pm 19.5 (mean $\pm \mathrm{SD}$ ) peak index value. Peak activity ranged from 35, which was the predetermined threshold for high activity, to 100, which is the maximum possible value. We expected that heifers would have periods of estrus of high intensity. Lactating cows in the same herd showed an average estrus intensity of $72.8 \pm 20.2$ peak index value (Madureira et al., 2013). Intensity of estrus can be influenced negatively by lactation and lameness, among other factors (Galina and Orihuela, 2007; Roelofs et al., 2010). Estrus peak activity has been shown to have a negative linear relationship with milk production in some (Valenza et al., 2012; López-Gatius et al., 2005) but not all (Madureira et al., 2013) reports. Factors influencing estrus expression are mainly absent in heifers, resulting in generally better reproductive performance for this category of cattle.

As observed with Heatime, IceTag data recorded estrus with high intensity in this study. Number of steps/ hour was $371 \pm 91$ (mean \pm SD) during estrus and 87 \pm 28 during baseline. The mean relative increase in walking activity during estrus was $360 \pm 170 \%$ baseline walking activity. Fold increase in activity of heifers during estrus measured by neck-mounted tags has been reported to be 2.75 (Løvendahl and Chagunda, 2010). The methodology used to obtain measurements of estrus intensity from IceTag sensors is based on raw data. Heatime, on the other hand, reports an index value that is weighted based on the activity of the previous week and can only increase up to an index value of 100. Use of raw activity might be a better measurement of intensity but it is more sensitive to day-to-day variations. Using a different data set of lactating cows (data not shown), we observed that the Heatime index activity is an approximate mirror value of the SD from activity from nonestrus days. An index value of 


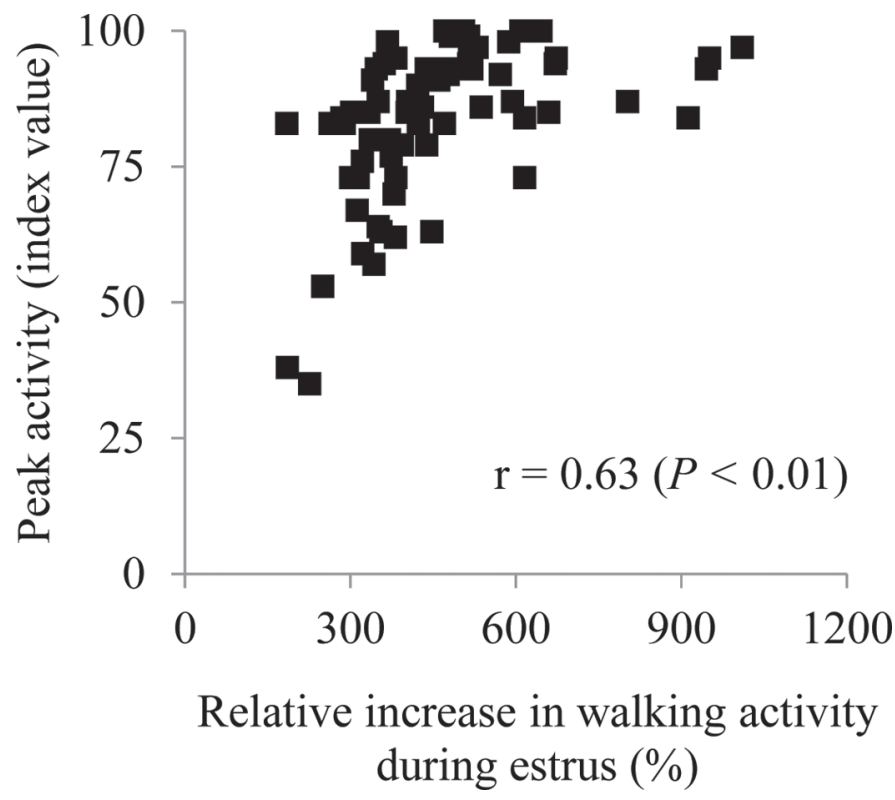

Figure 1. Correlation among measurements of estrus intensity by Heatime (collar-mounted accelerometer; estrus activity shown as peak index value, which was calculated by manufacturer's algorithm; SCR Engineers Ltd., Netanya, Israel) and IceTag (leg-mounted pedometer; estrus activity shown as relative increase in number of steps relative to the $3 \mathrm{~d}$ before the estrus episode; IceRobotics Ltd., Edinburgh, UK) for estrus episodes of freestall-housed Holstein heifers at breeding age (12 mo of age to confirmation of pregnancy).

35 (threshold) represents roughly 3.5 SD from basal activity, which could be translated into approximately a 2-fold increase.

Although differences exist between systems, measurements of intensity were correlated $(\mathrm{r}=0.63 ; P<$ 0.01; Figure 1). Measurements of intensity were comparable for lower intensity episodes, but those with a peak index value $>80$ are equivalent to a wide range of relative increase in activity. Heatime algorithmic processing imposes an upper limit for activity. Because of this characteristic, the greater the peak index value, the greater the observed range of relative increase in activity.

Mean $( \pm \mathrm{SD})$ duration of estrus episodes measured by Heatime was $14.3 \pm 4.1 \mathrm{~h}$, ranging from 4 to 22 h. Aungier et al. (2012), using Heatime, reported mean estrus durations of 8.4 and $10.8 \mathrm{~h}$ for the first and subsequent postpartum ovulations, respectively. If visual observation or mount detectors are used as the method for detection of estrus, the duration of an episode is determined as the period of acceptance of mount. This period lasts 5.6 to $7.6 \mathrm{~h}$ for lactating cows (At-Taras and Spahr, 2001; Lopez et al., 2004; Rivera et al., 2010) and $9.2 \mathrm{~h}$ for heifers (Silper et al., 2015). The relationship between duration of standing estrus and duration of increased activity should be further studied. Peralta et al. (2005) observed that onset of estrus of lactating cows varies with time of day when detected by pedometers, but not when mount detectors were used. At-Taras and Spahr (2001), also working with lactating cows, observed that duration of standing estrus (approximately $6 \mathrm{~h}$ ) and high activity counts (approximately $10 \mathrm{~h}$ ) overlapped by 3.6 or $6 \mathrm{~h}$, according to 2 experiments. Neither of these articles reported the difference in hour of onset between the detection methods.

It is speculated that the number of observed mounts per episode of estrus has been decreasing in lactating cows over the last decades. It has been reported that only $45 \%$ of cows show standing behavior during estrus (Roelofs et al., 2004). Lopez et al. (2004) observed 6 mounts/estrus in lactating cows, and Rivera et al. (2010) reported even fewer (4 mount/estrus) in cows treated with recombinant bST. The low number of mounts/estrus episode and the low percentage of animals showing standing behavior suggest that the use of secondary signs of estrus or changes in walking activity might be important to achieve desirable levels of estrus detection. Walking activity is likely a more accurate tool for determining start and end of estrus than visual observation of mounting and standing behavior.

Duration of estrus measured by IceTag $(15.0 \pm 4.0$ $\mathrm{h}$; mean $\pm \mathrm{SD}$ ) was correlated with that measured by Heatime $(\mathrm{r}=0.60 ; P<0.01)$. The mean estrus duration difference between IceTag and Heatime was $0.7 \pm$ $3.5 \mathrm{~h}$ (Figure 2). Seventy-five percent of the duration differences ranged from -2 to $+2 \mathrm{~h}$, supporting the good agreement between systems.

In addition to the similarity in duration of estrus episodes, the systems also recorded onset hour and end hour with small differences. IceTag recorded estrus onset $3.5 \pm 4.3 \mathrm{~h}$ earlier than Heatime and the end of estrus $2.9 \pm 4.9 \mathrm{~h}$ earlier. Knowledge about the time of estrus onset is important to determine AI time. This is, in fact, one of the main advantages of using automated estrus detection technologies. With visual observation of standing to be mounted, it is possible to determine if a cow is in estrus but little can be said about whether that is the start or the end of the estrus episode. Once the time of high activity onset is known, interval to ovulation can be estimated and AI time determined (Stevenson et al., 2014). There is, however, a need for more research with diverse estrus detection systems. For Heatime, Valenza et al. (2012) reported mean intervals of $28.7 \mathrm{~h}$ from high activity onset to ovulation and $16.4 \mathrm{~h}$ from peak-weighted activity to ovulation. It is important to note that Valenza et al. (2012) observed a large variation in the interval between estrus onset and ovulation, which makes the determination of optimal AI timing less predictable. Given the differences in 


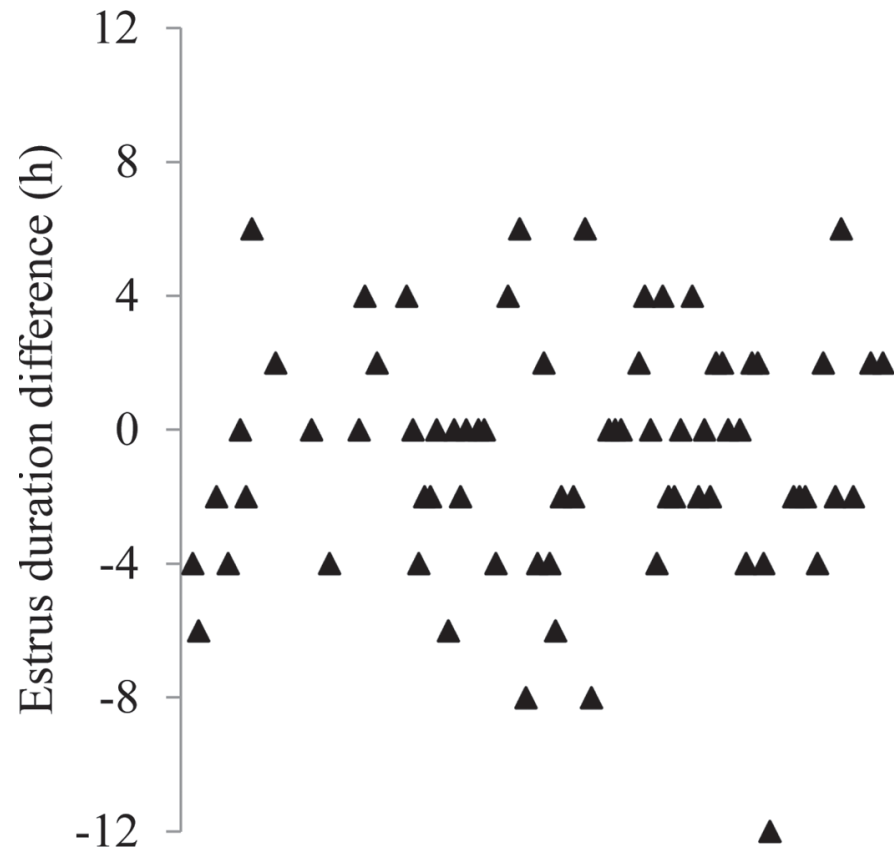

Figure 2. Difference in duration of estrus (h) as measured by 2 activity monitoring systems (IceTag estrus duration - Heatime estrus duration; IceTag: IceRobotics Ltd., Edinburgh, UK; Heatime: SCR Engineers Ltd., Netanya, Israel) for estrus episodes of freestall-housed Holstein heifers at breeding age (12 mo of age to confirmation of pregnancy).

reproductive performance between heifers and lactating cows, we can hypothesize that the interval from estrus onset to ovulation is less variable in heifers than in lactating cows.

The agreement between systems concerning timing of estrus detection was evidenced by the period of overlapping high activity. Considering time of onset and duration of estrus episodes, estrus episodes determined by IceTag and Heatime overlapped by $9.4 \pm 5.1 \mathrm{~h}$.

Duration and intensity are important components of estrus expression that directly influence AI submission rates. Heatime measurements of intensity and duration were correlated $(\mathrm{r}=0.64 ; P<0.01)$, suggesting that estrus is either well expressed in both features or it is poorly displayed in both. In contrast, IceTag measurements of intensity and duration of estrus were not correlated $(\mathrm{r}=0.13 ; P=0.26)$. Analysis of walking activity from IceTag data had minimal transformation compared with Heatime data. Perhaps corrections for circadian walking activity would smooth the data variability and improve the relationship between measurements of estrus intensity.

Number of baseline steps/hour measured by the IceTag system had a negative correlation $(P<0.01)$ with intensity of estrus in both sensors $(r=-0.37$ and -0.70 for Heatime and IceTag, respectively). Previous research (Silper et al., 2015) reported that heifers with greater level of baseline walking activity at 11 mo of age had a greater number of steps during estrus. In contrast, relative increase in activity and duration of estrus were not different among heifers with high versus low level of baseline activity (Silper et al., 2015). This might be an important indication that some heifers are more predisposed to better estrus expression than others, and also that estrus expression could be linked to pattern of activity during nonestrus periods.

Mean $( \pm \mathrm{SD})$ diameter of the preovulatory follicle was $15.7 \pm 2.6 \mathrm{~mm}$, and mean plasma estradiol concentration was $11.2 \pm 4.6 \mathrm{pg} / \mathrm{mL}$. These are similar to the values for dairy heifers reported by Sartori et al. (2004), who reported greater plasma estradiol concentrations in heifers than in lactating dairy cows, even though cows had larger preovulatory follicles. Accordingly, Wiltbank et al. (2006) reported the role of elevated metabolic rate on reduction of circulating estradiol in dairy cows, resulting in heifers having longer estrus episodes and greater pregnancy rates than lactating cows.

Estrus behavior is induced mainly by the effect of estradiol from the preovulatory follicle on the brain (Forde et al., 2011). Correlations between preovulatory follicle diameter, plasma estradiol concentration, and degree of estrus expression could be expected. Surprisingly, no correlation was found between preovulatory follicle diameter and plasma estradiol concentration ( $\mathrm{r}$ $=-0.02 ; P=0.87)$. According to measurements of either system, preovulatory follicle diameter was not correlated $(P>0.05)$ with duration of estrus (Table 1) and was only moderately correlated with intensity of estrus $(P<0.05)$. Plasma estradiol concentration, however, was not correlated with duration or intensity of estrus, independent of system (Table 1). Measurements of intensity and duration, from either Heatime or IceTag, were not different $(P>0.05)$ among episodes associated with small and large follicles or high and low concentrations of estradiol at time of estrus onset.

Few reports identified correlations between measurements from activity monitoring systems with plasma estradiol concentration or preovulatory follicle diameter. The results of the present study were contrary to our initial hypothesis that larger preovulatory follicle diameter and greater estradiol concentration would increase physical activity during estrus. One possibility for the lack of correlation could be that the true onset of estrus, and thus the best time for blood sample collection, is earlier than what is captured by activity monitors. This would result in inconsistent sampling time and possibly estradiol concentrations lower than peak concentration for some samples. Another possibility would be the randomness of collections in relation to feeding time as they were entirely dependent 
Table 1. Spearman rank correlations ${ }^{1}$ between physiological and automated measurements of true estrus episodes $^{2}$ of freestall-housed Holstein heifers at breeding age (12 mo of age to confirmation of pregnancy)

\begin{tabular}{lccccccc}
\hline & \multicolumn{2}{c}{ Heatime } & & \multicolumn{3}{c}{ IceTag } \\
\cline { 2 - 3 } \cline { 5 - 7 } Item & \multicolumn{2}{c}{ Intensity } & Duration & & Intensity & Duration & $\begin{array}{c}\text { Estrus } \\
\text { steps } / \mathrm{h}\end{array}$ \\
\hline Preovulatory follicle diameter & $0.20^{*}$ & $0.02^{\mathrm{NS}}$ & & $0.23^{*}$ & $-0.09^{\mathrm{NS}}$ & $0.11^{\mathrm{NS}}$ \\
& $(94)$ & $(94)$ & & $(73)$ & $(73)$ & $(73)$ \\
Plasma estradiol concentration & $0.04^{\mathrm{NS}}$ & $0.01^{\mathrm{NS}}$ & & $0.01^{\mathrm{NS}}$ & $0.01^{\mathrm{NS}}$ & $0.15^{\mathrm{NS}}$ \\
& $(77)$ & $(77)$ & & $(65)$ & $(65)$ & $(65)$ \\
\hline
\end{tabular}

${ }^{1}$ Spearman rank correlation coefficient (number of observations given in parentheses).

${ }^{2}$ False positive episodes were excluded from this analysis (17 out of 111 estrus episodes detected by Heatime); Heatime: SCR Engineers Ltd., Netanya, Israel; IceTag: IceRobotics Ltd., Edinburgh, UK.

$* P \leq 0.05 ;{ }^{N S} P>0.05$.

on the Heatime information. Vasconcelos et al. (2003) described acute changes in progesterone catabolism after feeding. Nonetheless, the lack of correlation may suggest that other factors, such as estradiol receptors in the brain or genetic traits, could be key determinants of estrus behavior. Moreover, behavioral estrus is apparently induced once a determined concentration of estradiol is reached; namely, in an "all-or-none" response (Allrich, 1994).

Signs of estrus, measured herein as mounting and standing to be mounted, clear vaginal mucus, and uterine tone, are important for on-farm assessment of the validity of activity peaks as estrus episodes. An increase in the number of estrus signs was related to greater duration and intensity of estrus as measured by Heatime only $(P<0.001$; Figure 3$)$.

An important consideration about automated estrus detection systems is how sensitive and specific they are. In this trial, we could not determine true negatives or false negatives for Heatime, thus only positive predictive value was calculated. True estrus episodes were determined from analysis of ovarian dynamics and plasma
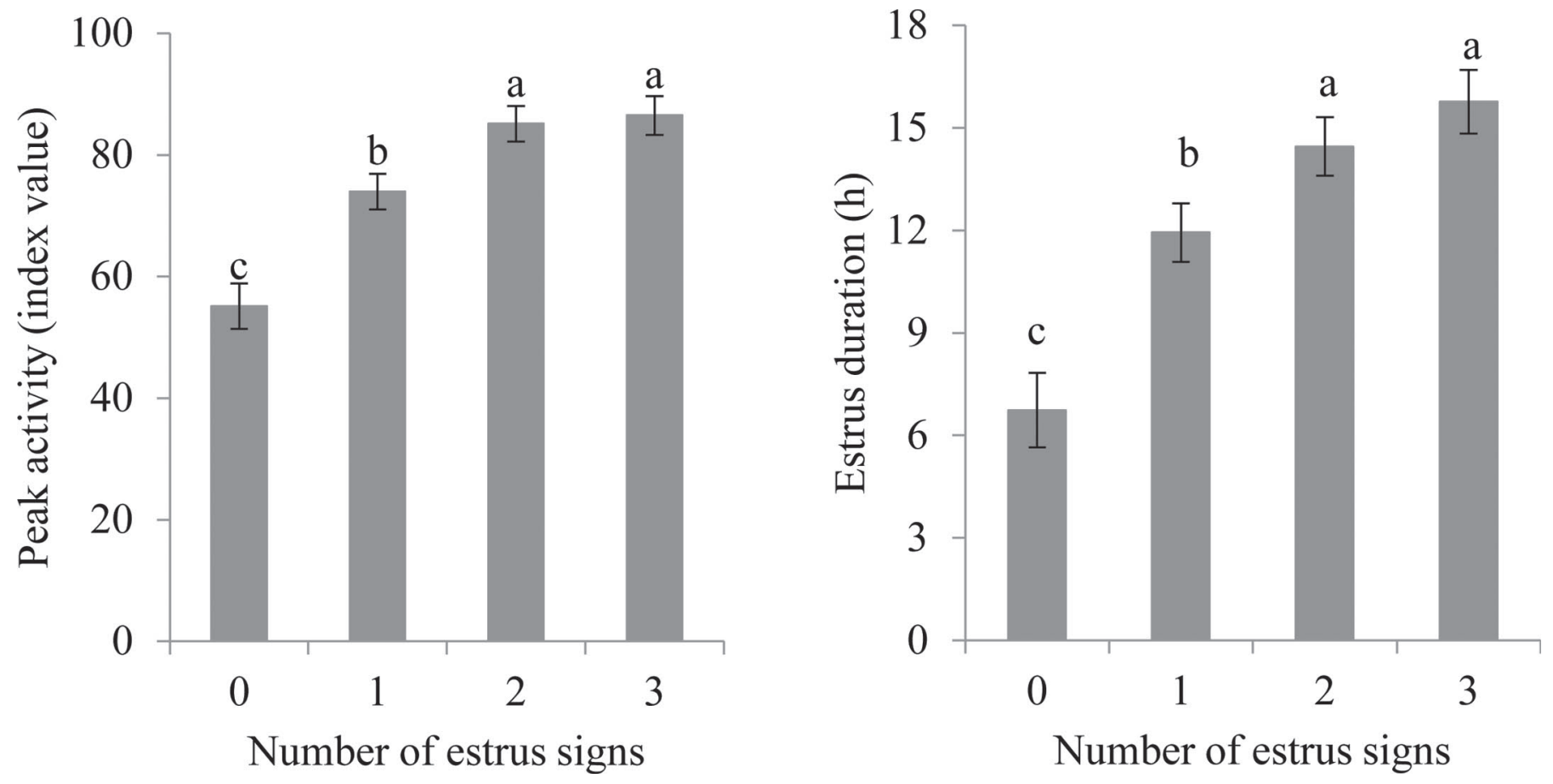

Figure 3. Least squares means \pm SEM of peak of activity (index value, intensity measurement) and duration (h) of estrus episodes of freestall-housed Holstein heifers at breeding age (12 mo of age to confirmation of pregnancy) measured by a collar-mounted accelerometer (Heatime; SCR Engineers Ltd., Netanya, Israel) according to the number of estrus signs observed at time of estrus onset. Observed estrus signs were clear vaginal mucus, uterine tone, and visual mounting activity, standing to be mounted, or both. Within each panel, different letters indicate statistical difference $(P<0.01$ for peak of activity; $P=0.02$ for estrus duration. 
Table 2. Performance of 2 automated estrus detection systems ${ }^{1}$ and characteristics of estrus expression by freestall-housed Holstein heifers at breeding age (12 mo of age to confirmation of pregnancy)

\begin{tabular}{lcc}
\hline Item & IceTag & Heatime \\
\hline Positive predictive value (\%) & $98.7(74 / 75)^{2}$ & $84.7(94 / 111)$ \\
Estrus intensity $^{3}$ (mean $\left.\pm \mathrm{SD}\right)$ & $360 \pm 170 \%$ & $77.3 \pm 19.5$ \\
Estrus duration (mean $\pm \mathrm{SD} ; \mathrm{h})$ & $15.0 \pm 4.0$ & $14.3 \pm 4.1$ \\
\hline${ }^{1}$ IceTag: IceRobotics Ltd., Edinburgh, UK; Heatime: SCR Engineers Ltd., Netanya, Israel. \\
${ }^{2}$ Values in parentheses indicate true positive episodes/all positive episodes. \\
${ }^{3}$ For IceTag, estrus intensity was calculated as follows: (relative increase in walking activity from baseline ac- \\
tivity = [(total estrus steps - total baseline steps)/total baseline steps] $\times$ 100\%. For Heatime, estrus intensity \\
was peak index value.
\end{tabular}

estradiol concentration. Positive predictive values were high for both systems (Table 2), implying high precision of estrus detection (low frequency of false positive alerts).

In addition to high precision of estrus detection, the systems had good agreement between measurements of estrus expression. Heifers had estrus episodes of high intensity and duration within expected values. The relationships between preovulatory follicle diameter, plasma estradiol concentration, and measurements of estrus expression were not consistent between the 2 systems. Heatime data showed better correlations overall than IceTag data. In contrast, data from IceTag sensors provided valuable information on raw activity during estrus and nonestrus periods. Variables such as concentration of estradiol and estrus signs should be analyzed independently for research purposes. Future research should assess the interval between estrus onset determined by different types of sensors and ovulation time.

\section{ACKNOWLEDGMENTS}

This study was supported by a contribution from the Dairy Research Cluster Initiative (Dairy Farmers of Canada, Agriculture and Agri-Food Canada, the Canadian Dairy Network, and the Canadian Dairy Commission; Ottawa, ON, Canada), the Natural Sciences and Engineering Research Council of Canada, and the Westgen Endowment Fund (Milner, BC, Canada). B. F. Silper is funded by the Science Without Borders program from $\mathrm{CNPq}$ (Conselho Nacional de Desenvolvimento Tecnológico, Brasília, Brazil). The authors also thank A. M. de Passillé, J. Rushen, G. Zdanowicz, and all students who assisted with the data collection at the UBC Dairy Education and Research Centre (Agassiz, BC, Canada).

\section{REFERENCES}

Allrich, R. D. 1994. Endocrine and neural control of estrus in dairy cows. J. Dairy Sci. 77:2738-2744. http://dx.doi.org/10.3168/jds. S0022-0302(94)77216-7.
At-Taras, E. E., and S. L. Spahr. 2001. Detection and characterization of estrus in dairy cattle with an electronic heatmount detector and an electronic activity tag. J. Dairy Sci. 84:792-798. http://dx.doi. org/10.3168/jds.S0022-0302(01)74535-3.

Aungier, S. P. M., J. F. Roche, M. Sheehy, and M. A. Crowe. 2012. Effects of management and health on the use of activity monitoring for estrus detection in dairy cows. J. Dairy Sci. 95:2452-2466. http://dx.doi.org/10.3168/jds.2011-4653.

Forde, N., M. E. Beltman, P. Lonergan, M. Diskin, J. F. Roche, and M. A. Crowe. 2011. Oestrous cycles in Bos taurus cattle. Anim. Reprod. Sci. 124:163-169. http://dx.doi.org/10.1016/j.anireprosci. 2010.08.025

Galina, C. S., and A. Orihuela. 2007. The detection of estrus in cattle raised under tropical conditions: what we know and what we need to know. Horm. Behav. 52:32-38. http://dx.doi.org/10.1016/j. yhbeh.2007.03.025.

Jónsson, R., M. Blanke, N. K. Poulsen, F. Caponetti, and S. Højsgaard. 2011. Oestrus detection in dairy cows from activity and lying data using on-line individual models. Comput. Electron. Agric. 76:6-15. http://dx.doi.org/10.1016/j.compag.2010.12.014.

Kiddy, C. A. 1977. Variation in physical activity as an indication of estrus in dairy cows. J. Dairy Sci. 60:235-243. http://dx.doi. org/10.3168/jds.S0022-0302(77)83859-9

Kirby, C. J., M. F. Smith, D. H. Keisler, and M. C. Lucy. 1997. Follicular function in lactating dairy cows treated with sustained-release bovine somatotropin. J. Dairy Sci. 80:273-285.

Lopez, H., L. D. Satter, and M. C. Wiltbank. 2004. Relationship between level of milk production and estrous behavior of lactating dairy cows. Anim. Reprod. Sci. 81:209-223.

López-Gatius, F., M. López-Béjar, M. Fenech, and R. H. F. Hunter. 2005. Ovulation failure and double ovulation in dairy cattle: Risk factors and effects. Theriogenology 63:1298-1307. http://dx.doi. org/10.1016/j.theriogenology.2004.06.010.

Løvendahl, P., and M. G. G. Chagunda. 2010. On the use of physical activity monitoring for estrus detection in dairy cows. J. Dairy Sci. 93:249-259. http://dx.doi.org/10.3168/jds.2008-1721.

Madureira, A. M. L., T. A. Burnett, B. F. Silper, N. Dinn, and R. L. A. Cerri. 2013. Factors affecting expression of estrus of lactating dairy cows using activity monitors. J. Dairy Sci. 96(E-Suppl. 1):600-601. (Abstr.)

McGowan, J. E., C. R. Burke, and J. G. Jago. 2007. Validation of a technology for objectively measuring behaviour in dairy cows and its application for oestrous detection. Proc. N.Z. Soc. Anim. Prod. $67: 136-142$.

Nebel, R. L., M. G. Dransfield, S. M. Jobst, and J. H. Bame. 2000. Automated electronic systems for the detection of oestrus and timing of AI in cattle. Anim. Reprod. Sci. 60-61:713-723.

Nielsen, L. R., A. R. Pedersen, M. S. Herskin, and L. Munksgaard. 2010. Quantifying walking and standing behaviour of dairy cows using a moving average based on output from an accelerometer. Appl. Anim. Behav. Sci. 127:12-19. http://dx.doi.org/10.1016/j. applanim.2010.08.004

Peralta, O. A., R. E. Pearson, and R. L. Nebel. 2005. Comparison of three estrus detection systems during summer in a large com- 
mercial dairy herd. Anim. Reprod. Sci. 87:59-72. http://dx.doi. org/10.1016/j.anireprosci.2004.10.003.

Rae, D. O., P. J. Chenoweth, M. A. Giangreco, P. W. Dixon, and F. L. Bennet. 1999. Assessment of estrus detection by visual observation and electronic detection methods and characterization of factors associated with estrus and pregnancy in beef heifers. Theriogenology 51:1121-1132.

Rivera, F., C. Narciso, R. Oliveira, R. L. A. Cerri, A. Correa-Calderón, R. C. Chebel, and J. E. P. Santos. 2010. Effect of bovine somatotropin $(500 \mathrm{mg}$ ) administered at ten-day intervals on ovulatory responses, expression of estrus, and fertility in dairy cows. J. Dairy Sci. 93:1500-1510. http://dx.doi.org/10.3168/jds.2009-2489.

Roelofs, J. B., E. G. Bouwman, S. J. Dieleman, F. J. C. M. Van Eerdenburg, L. M. T. E. Kaal-Lansbergen, N. M. Soede, and B. Kemp. 2004. Influence of repeated rectal ultrasound examinations on hormone profiles and behaviour around oestrus and ovulation in dairy cattle. Theriogenology 62:1337-1352. http://dx.doi. org/10.1016/j.theriogenology.2004.02.002.

Roelofs, J. B., F. López-Gatius, R. H. F. Hunter, F. J. C. M. van Eerdenburg, and C. Hanzen. 2010. When is a cow in estrus? Clinical and practical aspects. Theriogenology 74:327-344. http://dx.doi. org/10.1016/j.theriogenology.2010.02.016.

Roelofs, J. B., F. J. C. M. van Eerdenburg, N. M. Soede, and B. Kemp. 2005. Various behavioral signs of estrous and their relationship with time of ovulation in dairy cattle. Theriogenology 63:13661377. http://dx.doi.org/10.1016/j.theriogenology.2004.07.009.

Sartori, R., J. M. Haughian, R. D. Shaver, G. J. M. Rosa, and M. C. Wiltbank. 2004. Comparison of ovarian function and circulating steroids in estrous cycles of Holstein heifers and lactating cows.
J. Dairy Sci. 87:905-920. http://dx.doi.org/10.3168/jds.S00220302(04)73235-X

Senger, P. L. 1994. The estrus detection problem: New concepts, technologies, and possibilities. J. Dairy Sci. 77:2745-2753. http:// dx.doi.org/10.3168/jds.S0022-0302(94)77217-9.

Silper, B. F., I. Robles, A. M. L. Madureira, T. A. Burnett, M. M. Reis, A. M. de Passillé, J. Rushen, and R. L. A. Cerri. 2015. Automated and visual measurements of estrous behavior and their sources of variation in Holstein heifers I: Walking activity and behavior frequency. Theriogenology http://dx.doi.org/10.1016/j. theriogenology.2014.12.029.

Stevenson, J. S., S. L. Hill, R. L. Nebel, and J. M. Dejarnette. 2014. Ovulation timing and conception risk after automated activity monitoring in lactating dairy cows. J. Dairy Sci. 97:4296-4308. http://dx.doi.org/10.3168/jds.2013-7873.

Valenza, A., J. O. Giordano, G. Lopes, L. Vincenti, M. C. Amundson, and P. M. Fricke. 2012. Assessment of an accelerometer system for detection of estrus and treatment with gonadotropin-releasing hormone at the time of insemination in lactating dairy cows. J. Dairy Sci. 95:7115-7127. http://dx.doi.org/10.3168/jds.2012-5639.

Vasconcelos, J. L. M., S. Sangsritavong, S. J. Tsai, and M. C. Wiltbank. 2003. Acute reduction in serum progesterone concentrations after feed intake in dairy cows. Theriogenology 60:795-807. http://dx.doi.org/10.1016/S0093-691X(03)00102-X.

Wiltbank, M., H. Lopez, R. Sartori, S. Sangsritavong, and A. Gümen. 2006. Changes in reproductive physiology of lactating dairy cows due to elevated steroid metabolism. Theriogenology 65:17-29. http://dx.doi.org/10.1016/j.theriogenology.2005.10.003. 